\title{
Comportamento socioambiental do consumidor: um estudo com universitários do interior paulista
}

\author{
Helenita Rodrigues da Silva Tamashiro ${ }^{a *}$, Wandrey Antonio Murarib, \\ Sônia Valle Walter Borges de Oliveira ${ }^{c}$, Claudia Rosa Acevedo ${ }^{\mathrm{d}}$ \\ a*hrstamashiro@ibest.com.br, FEA-USP, Brasil \\ bwandreym@hotmail.com, FA0, Brasil \\ 'soniavw@terra.com.br, FEA-RP-USP, Brasil \\ dclaudiaraac@uol.com.br, EACH-USP, Brasil
}

\begin{abstract}
Resumo
A Responsabilidade Social Corporativa vem se consolidando cada vez mais, dentro de um cenário de mercado muito competitivo e de consumidores mais exigentes e seletivos. Assim, o objetivo desta pesquisa foi verificar se as ações de responsabilidade socioambiental influenciam no processo de decisão de compra dos consumidores. Para tanto, foram aplicados 100 questionários a alunos de um curso de administração de uma universidade no Estado de São Paulo, sendo que, 68 questionários foram validados e analisados, aplicando-se a estatística descritiva. Os resultados demonstraram que: i) as ações socioambientais não afetam o processo de compra desses consumidores; ii) que as empresas devem informar aos seus públicos em quais ações sociais e ambientais estão envolvidas e quais são os impactos positivos que suas ações têm gerado à biodiversidade e à sociedade.
\end{abstract}

Palavras-chave

Responsabilidade socioambiental. Decisão de compra. Lealdade do consumidor. Comportamento do consumidor.

\section{Introdução}

As forças políticas, econômicas e sociais são responsáveis pela criação de um ambiente mercadológico competitivo e volátil, no qual produtos e serviços deixaram de ser fatores de diferenciação para uma empresa. Desta forma, a preocupação com a questão da qualidade ambiental tem resultado em sérios questionamentos nas diversas atividades dos diferentes setores da economia global (THUROW, 1997). Assim, nas últimas décadas, a prática da Responsabilidade Social Corporativa (RSC) vem se consolidando em escalas cada vez mais multidimensionais e sistêmicas no âmbito das organizações, dada a interdependência entre os diversos stakeholders (clientes, fornecedores, acionistas, governo, mídia, comunidade etc.). Analisando esta questão, Wagner (2003) destaca que, nos últimos anos, as questões ambientais têm recebido muita atenção, reflexão e crescente preocupação pública e de sensibilização do problema ambiental.

Dentre as alternativas que se apresentam, é possivel observar a geração de discussões em torno da Responsabilidade Social das empresas, consideradas fundamentais na promoção do bem-estar, que cada vez mais depende de uma ação cooperativa e integrada de todos os setores da economia, cujo processo de desenvolvimento contemple metas voltadas para a preservação do meio ambiente e a promoção dos direitos humanos (LIMA, 2002). Neste contexto, surgem alguns movimentos como o Consumerismo, denominado por Antonides e Raaij (1998) como um movimento social dirigido aos interesses do consumidor. Seu objetivo é obter mais informação, proteção, leis e garantias para os consumidores, o que, segundo Carrigan (1995), significa um grande desafio para as organizações. Estas são obrigadas a produzir não apenas lucros para os seus acionistas, mas também beneficiar os diversos stakeholderes. Mohr e Webb (2005) e Mohr, Webb e Harris (2001) 
destacam que tal postura influencia diretamente a lucratividade das empresas, principalmente quando se observa que cada vez menos as pessoas estão julgando uma empresa apenas por seus fatores econômicos.

Face a este contexto, as relações comerciais entre as empresas e seus clientes tornaram-se mais complexas e passaram a exigir novos padrões de competitividade a partir de atributos que vão além de preço dos produtos, qualidade e suporte pós-venda. De fato, Thurow (1997) assinala que as forças políticas, econômicas e sociais são responsáveis pela criação de um ambiente mercadológico competitivo e volátil, no qual produtos e serviços deixaram de ser fatores de diferenciação para uma empresa. Esta ênfase, segundo Levek et al. (2002), consiste na relevância para a melhoria da imagem da organização. Estes mesmos autores sustentam que a Responsabilidade Social tem sido utilizada como um meio de demonstração do compromisso que a empresa assume perante a comunidade.

Para atender e conquistar consumidores cada vez mais exigentes e conscientes do seu compromisso com o exercício da sua cidadania, as companhias precisam demonstrar que possuem uma postura correta, tanto no que diz respeito às leis, aos direitos humanos e ao meio ambiente (D’AMBROSIO, 1998). Nessa perspectiva, nas últimas décadas algumas ações vêm gerando debates e recebendo atenção especial nas comunidades acadêmica e empresarial com o escopo de se tentar integrar a Responsabilidade Social ao planejamento estratégico das organizações, especificamente no tocante ao meio ambiente, por se tratar de uma variável que tem sido levada em consideração pelas empresas brasileiras na condução de seus negócios (MOTTA; ROSSI, 2001; THOGERSEN; OLANDER, 2002; GILG; BARR; FORD, 2005; MACKENZIE, 1990; AMINE, 2003).

Considerando a contextualização aqui explicitada, parece pertinente a realização de um estudo sob a ótica do comportamento de compra dos consumidores frente às ações de responsabilidade socioambiental, uma vez que o que está em jogo na opinião de Fortes (1992) não é apenas o combate à poluição, mas todo um processo voltado para a satisfação das necessidades, sem necessariamente comprometer e colocar em risco os direitos humanos no presente $\mathrm{e}$ no futuro. Complementando este raciocínio, MintuWimsatt e Bradford (1995) relatam que o aumento de lançamentos de produtos "verdes" por parte das empresas não se trata apenas de um ajuste com as questões de legislação específica, mas também de uma resposta mercadológica às pressões que grupos de consumidores começaram a exercer, desde o início dos anos 90, mediante uma maior preocupação com os aspectos relacionados ao meio ambiente.
Considerando todos os aspectos aqui explicitados, dentro de um contexto em que as discussões sobre as experiências baseadas no consumo tornaram-se um tema dominante na literatura que trata das preferências dos consumidores (BÄCKSTROÖM; JOHANSSON, 2006), a seguinte questão de pesquisa motivou a implementação deste estudo: a responsabilidade socioambiental influência a decisão de compra dos consumidores? No intuito de responder a tal questionamento, o objetivo desta pesquisa foi verificar se as ações de responsabilidade socioambiental influenciam o processo de decisão de compra dos consumidores.

$\mathrm{Na}$ busca do alcance do objetivo proposto, procurou-se organizar o trabalho a partir da seguinte estrutura: primeiro, realiza-se uma revisão bibliográfica sobre o assunto proposto, enfatizando os principais conceitos relacionados ao tema proposto. Em seguida, discutem-se os aspectos metodológicos adotados na pesquisa. Posteriormente, os resultados são apresentados e discutidos, sob a luz da revisão da literatura e, finalmente, são apresentadas as considerações finais, as limitações do estudo e as sugestões para pesquisas adicionais. As motivações, bem como a justificativa quanto à realização do estudo, são apresentadas na seção a seguir.

\section{Justificativa do trabalho}

Várias constatações motivaram a realização do presente estudo. Uma delas diz respeito à relevância da análise e entendimento das necessidades e do comportamento dos consumidores, tanto do ponto de vista de se identificar oportunidades de desenvolvimento e lançamento de novos produtos (KLEEF; TRIJP; LUNING, 2005; ATUAHENE-GIMA, 1996), como do ponto de vista de se identificar onde e por que as pessoas compram (SOLOMON, 1996). 0 entendimento de todos esses aspectos evidencia-se como um tema chave para a sustentabilidade das atividades de marketing, cujos desafios são o desenvolvimento e o lançamento de novos produtos que satisfaçam as necessidades dos consumidores, aspectos considerados como pontos de partida para a sobrevivência das empresas, segundo Costa e Jongen (2006). Além do mais, para se otimizar a eficácia e a eficiência das atividades de marketing é importante entender como os consumidores percebem os produtos, como suas necessidades são formadas e influenciadas e como eles fazem suas escolhas baseadas nessas necessidades (KLEEF; TRIJP; LUNING, 2005).

As premissas acima permitem inferir que a realização de pesquisas de campo que procuram investigar a relação entre os fatores socioambientais e o comportamento dos consumidores é algo ainda 
embrionário, principalmente no Brasil, que possui poucos estudos estatísticos que validam esta questão (MORAIS et al., 2006). No campo específico do conhecimento da pesquisa proposta, foram localizados alguns trabalhos que, apesar de apresentarem enfoques semelhantes, os objetos, bem como os objetivos de estudo, são diferentes. Segundo Ashley et al. (2005), muitas empresas, acadêmicos e, principalmente, a mídia vêm enfatizando de forma demasiada apenas a abordagem instrumental da RSC, concebendo-a exclusivamente como forma de melhorar a imagem da empresa, de identificar novas oportunidades e testar novas tecnologias e produtos, adquirindo, assim, vantagens competitivas. 0 interesse de outros pesquisadores consiste em investigar a atitude do consumidor frente a empresas voltadas para ações de RSC, como, por exemplo, uma pesquisa conduzida por Brown e Dacin (1997), cuja conclusão é a de que a RSC exerce influência positiva nas crenças e atitudes dos consumidores. 0 Quadro 1 traz uma sintese desses trabalhos.

Partindo do pressuposto de se tratar de um tema relevante para o atual contexto, em que diariamente são discutidos os efeitos da degradação da biodiversidade, a realização da pesquisa proposta neste artigo constitui-se em uma oportunidade de se ampliar as discussões a esse respeito. A relevância da pesquisa proposta se estende também à comunidade acadêmica, pelo quadro de referências bibliográficas que poderá servir como fonte de informação na implementação de pesquisas adicionais no campo científico.

\section{Aspectos conceituais da Responsabilidade Social}

A Responsabilidade Social é concebida por Melo Neto e Froes (1999) como sendo o comprometimento da empresa em tomar uma decisão de participar diretamente das ações comunitárias na região em que está presente e minorar possíveis danos ambientais decorrentes do tipo de atividade que a empresa venha a exercer. Gil (2001) admite que as empresas devem assumir valores éticos, proteger o meio ambiente, respeitar seus funcionários e comprometer-se com a comunidade. Entretanto, alguns estudiosos sobre o assunto encaram a questão da Responsabilidade Social sob cinco abordagens, resumidas no Quadro 2.

Levek et al. (2002) descrevem a Responsabilidade Social nas empresas como sendo uma coerência ética nas práticas e relações com seus diversos públicos, contribuindo significativamente para o desenvolvimento contínuo das pessoas, das comunidades e do meio

Quadro 1. Pesquisas sobre Responsabilidade Social.

\begin{tabular}{|c|l|}
\hline Autor/ano & \multicolumn{1}{c|}{ Objetivos do estudo } \\
\hline $\begin{array}{c}\text { Motta e Rossi } \\
(2001)\end{array}$ & $\begin{array}{l}\text { Verificar se o meio ambiente é um dos fatores levados em consideração pelos consumidores quando decidem suas compras } \\
\text { de bens de conveniência. }\end{array}$ \\
\hline $\begin{array}{c}\text { Trevisan } \\
(2002)\end{array}$ & $\begin{array}{l}\text { Mostrar a importância da prática da Responsabilidade Social pelas empresas e da divulgação de suas atividades sociais por } \\
\text { meio do Balanço Social. }\end{array}$ \\
\hline $\begin{array}{c}\text { Morais et al. } \\
(2006)\end{array}$ & $\begin{array}{l}\text { Investigar a relação entre RSC e intenção de compra do consumidor, em um contexto em que a empresa pratica um preço } \\
\text { maior do que o da concorrência. }\end{array}$ \\
\hline $\begin{array}{c}\text { Fedato } \\
(2005)\end{array}$ & $\begin{array}{l}\text { Estudar a atuação das empresas para conhecer suas características, identificar as formas como são avaliados os resultados } \\
\text { dessas ações e verificar se existem possibilidades de se conciliar a obtenção de resultados econômicos e sociais. }\end{array}$ \\
\hline
\end{tabular}

Quadro 2. Abordagens conceituais da Responsabilidade Social.

\begin{tabular}{|c|l|}
\hline Autor/ano & \multicolumn{1}{c|}{ Objetivos do estudo } \\
\hline $\begin{array}{c}\text { Friedman } \\
(1988)\end{array}$ & $\begin{array}{l}\text { Como aspectos “liberais, neoliberais e afins”. A responsabilidade social do capital consiste no uso dos recursos, dedicando- } \\
\text { se às atividades destinadas a aumentar seus lucros até os limites das regras do jogo, o que significa participar de uma } \\
\text { competição livre e aberta, sem enganos ou fraudes. }\end{array}$ \\
\hline $\begin{array}{c}\text { Freitas } \\
(1997)\end{array}$ & $\begin{array}{l}\text { É vista como uma “legitimação social”. Segundo o ponto de vista da autora, as grandes empresas ou organizações modernas } \\
\text { constituem um novo polo da legitimação social e como o lugar que pode responder pelo esfacelamento dos vínculos sociais } \\
\text { e pelas questões identitárias que constroem. }\end{array}$ \\
\hline $\begin{array}{c}\text { Srour } \\
(1998)\end{array}$ & $\begin{array}{l}\text { É vista como “uma questão ética”. A Responsabilidade Social está diretamente relacionada com a questão da ética: estão } \\
\text { indubitavelmente entrelaçadas, sendo que esta última reflete o comprometimento com o futuro. }\end{array}$ \\
\hline $\begin{array}{c}\text { Drucker } \\
(2001)\end{array}$ & $\begin{array}{l}\text { É concebida como "responsabilidade social corporativa”. Não existe mais ninguém, na sociedade das organizações, para } \\
\text { cuidar da própria sociedade. Por este motivo, as organizações precisam assumir a Responsabilidade Social e agir de forma } \\
\text { responsável, dentro dos limites da sua competência, sem colocar em risco sua capacidade de desempenho. }\end{array}$ \\
\hline $\begin{array}{c}\text { Tomei e lerner } \\
\text { (2004) }\end{array}$ & $\begin{array}{l}\text { É encarada como um “modismo", por se tratar de uma "forma de comportamento que é temporariamente adotada por } \\
\text { uma proporção identificável de membros de um grupo social, porque este comportamento escolhido é percebido como } \\
\text { socialmente apropriado para o tempo e para a situação". }\end{array}$ \\
\hline
\end{tabular}

Fonte: elaborado pelos pesquisadores, com base na literatura citada. 
ambiente, além de conquistar o respeito e a preferência dos consumidores. Também abordam que a relevância de atividades sociais pode propiciar conflitos de interesses, uma vez que a maximização de lucro é um fator indispensável na organização. A mobilização de movimentos nacionais e internacionais criou, em 2001, o Fórum Social Mundial, que é realizado anualmente no Brasil. Esses acontecimentos provocaram uma série de transformações na comunidade empresarial, que vêm se consolidando nos últimos dez anos, em torno de investimentos sociais.

\section{Responsabilidade Social e comportamento de compra do consumidor}

Diversos pesquisadores têm dedicado atenção especial aos estudos relacionados ao Comportamento do Consumidor. Dentre eles, destacam-se os trabalhos de Nicosia (1966), Levy (2005) e Ajzen (1991).

De acordo com Demirdjian e Senguder (2004), cada vez mais o comportamento do consumidor tem feito parte da agenda das áreas de marketing, uma vez que este coloca o consumidor no centro das suas estratégias de marketing. Além disso, ele constitui um quadro conceitual que orienta o pensamento estratégico para a realização bem sucedida de segmentação dos mercados. Mostrando-se concordantes com essa linha de pensamento, Sheth, Mittal e Newman (2001) assinalam que conhecer o que os consumidores querem e como eles tomam suas decisões sobre a compra é fundamental para o êxito das organizações.

0 termo "consumidor" é convencionalmente utilizado para se referir apenas aos mercados de bens de consumo, ao passo que "cliente" é adotado para referir-se às relações comerciais entre as organizações
(SHETH; MITTAL; NEWMAN, 2001). Segundo Kotler e Keller (2006), comportamento do consumidor é um campo que procura investigar como pessoas, grupos e organizações selecionam, compram, usam e descartam artigos, serviços, ideias ou experiências para satisfazer suas necessidades e desejos.

Engel, Blackwell e Miniard (1995) por sua vez, definem o comportamento do consumidor como o conjunto das atividades diretamente envolvidas em obter, consumir e dispor de produtos e serviços, incluindo os processos decisórios que antecedem e sucedem essas ações. Diversos fatores, como as diferenças individuais, as influências ambientais e os processos psicológicos, podem afetar o seu comportamento de compra e de consumo (ENGEL; BLACKWELL; MINIARD, 1995). Complementando este raciocínio, Jacoby e Kyner (1973) afirmam que mesmo um cliente satisfeito pode não ser um cliente leal, dada a influência de fatores situacionais ou até mesmo de conveniência. Fombrun, Gardberg e Barnett (2000), por exemplo, argumentam que a atividade socialmente responsável ajuda a empresa a reforçar suas relações com a comunidade local e com seus empregados. Churchill e Peter (2000), Sheth, Mittal e Newman (2001) e Kotler e Armstrong (1993) consideram que os fatores mais relevantes e que podem influenciar o comportamento de compra dos consumidores são respectivamente: os valores culturais, psicológicos, geográficos, sociais e pessoais, conforme pode ser observado no Quadro 3.

Convém destacar que o consumo sustentável enquanto forma de consumo que utiliza os recursos naturais para satisfazer às necessidades, sem necessariamente comprometer as necessidades e aspirações das gerações futuras, advém das mudanças de atitudes dos consumidores e da sociedade em geral. Para efeito deste estudo, adotou-se o conceito de consumo sustentável respaldado pelo

Quadro 3. Fatores influenciadores no comportamento do consumidor.

\begin{tabular}{|c|l|}
\hline Fatores & \multicolumn{1}{c|}{ Descrição } \\
\hline Culturais & $\begin{array}{l}\text { Constitui um dos primeiros fatores que podem determinar a forma de pensar de um indivíduo. Crescendo em uma } \\
\text { determinada sociedade, o indivíduo vai adquirindo valores, tendo percepções, preferências e criando comportamentos } \\
\text { refletidos deste meio social. É no convivio com as pessoas que ele vai definir a sua personalidade ao longo dos anos. Para } \\
\text { os autores, cada classe pode apresentar preferências e condições distintas sobre alguns produtos e marcas como vestuário, } \\
\text { móveis, lazer, produtos alimentícios etc. }\end{array}$ \\
\hline Sociais & $\begin{array}{l}\text { São os grupos de referência como a família, amigos vizinhos e personalidades. Eles têm uma influência direta ou indireta } \\
\text { sobre as atitudes do comportamento das pessoas. Existe a chamada família de orientação, composta pelos pais. Com eles, a } \\
\text { pessoa pode influenciar-se através da religião, política e comportamento pessoal. Pode haver também influência da família } \\
\text { de procriação que é a presença do marido, mulher ou filhos. }\end{array}$ \\
\hline Pessoais & $\begin{array}{l}\text { As principais características pessoais influenciadoras são: a) idade e ciclo de vida: as pessoas não compram a vida toda os } \\
\text { mesmos produtos; b) ocupação: a ocupação de uma pessoa está relacionada com os bens ou serviços que ela pode adquirir; } \\
\text { c) condiços econômicas: refere-se à situação em que o consumidor pode estar vivendo em seu país como inflação, recessão, } \\
\text { condições de empréstimo, taxa de juros etc.; d) estilo de vida: as pessoas podem pertencer à mesma classe social, ou ter } \\
\text { a mesma ocupação, mas podem ter estilos de vida diferentes, o que significa que cada indivíduo cria a sua personalidade. }\end{array}$ \\
\hline Psicológicos & São constituídos pelos seguintes fatores: motivação, percepção, aprendizado, crenças e atitudes. \\
\hline Fonte: elaborado pelos pesquisadores, a partir de Churchill e Peter (2000), Sheth, Mittal e Newman (2001) e Kotler e Armstrong (1993).
\end{tabular}


Programa das Nações Unidas para o Desenvolvimento (PROGRAMA..., 1998, p. 65), que o concebe como:

0 fornecimento de serviços e de produtos correlatos, que preencham as necessidades básicas e deem uma melhor qualidade de vida, ao mesmo tempo em que se diminui o uso de recursos naturais e de substâncias tóxicas, assim como as emissões de resíduos e de poluentes durante o ciclo de vida do serviço ou do produto, com a ideia de não se ameaçar as necessidades das gerações futuras.

Para Dowling (1993), as associações cognitivas dos consumidores em relação às empresas podem ser consideradas um ativo estratégico. Além disso, podem ser também consideradas como vantagens competitivas aliadas à sustentabilidade (AAKER, 1996). As questões ambientais têm gerado fortes impactos sobre o comportamento dos consumidores. Mohr e Webb (2005) acreditam que cada vez menos as pessoas estão julgando uma empresa apenas por seus fatores econômicos.

Utilizando dados de uma pesquisa promovida pelo Instituto Ethos, pelo jornal Valor Econômico e conduzida pelo Indicador Opinião Pública, Trevisan (2002) destaca que 56\% dos 1.002 brasileiros entrevistados consideram a Responsabilidade Social um elemento importante para dizer se a empresa é boa ou ruim, ao passo que $24 \%$ dos entrevistados disseram ter prestigiado uma empresa socialmente responsável, comprando seus produtos ou falando bem dela para outras pessoas e 19\% disseram ter punido uma empresa em situação oposta, fazendo o contrário.

Mostrando-se concordantes com a linha de pensamento acima, Dick, Chakravarti e Biehal (1990), sugerem que, quando um consumidor identifica um produto com uma empresa, surge uma oportunidade de uma avaliação genérica da empresa influenciar a avaliação do produto. Assim, Gomes (2006) defende a ideia de que o foco da sociedade contemporânea não pode mais estar direcionado apenas para a produção de riquezas, mas para a sua distribuição e sua melhor utilização. É necessária uma verdadeira e efetiva mudança de postura na relação entre o homem e a natureza, em que não haja dominação, mas harmonia entre eles.

A revisão da literatura deixa evidências de que, cada vez mais, a análise dos fatores que influenciam a decisão de compra configura-se um tema de grande relevância no campo científico, especialmente nos estudos relacionados com a investigação das atitudes dos consumidores frente a empresas voltadas para ações de RSC.

Segundo Titus e Bradford (1996), os consumidores vêm buscando mais informações sobre seus direitos e sobre a responsabilidade das empresas perante a sociedade; daí, a importância de se compreender melhor a relação entre o comportamento socialmente responsável das empresas e a decisão de compra. Pesquisa conduzida por Brown e Dacin (1997) concluiu que a RSC exerce tênue influência sobre as atitudes dos consumidores. Nessa mesma linha, destacam-se ainda os trabalhos de Mohr e Webb (2005), Motta e Rossi (2001), Morais et al. (2006), Trevisan (2002), Fedato (2005), Serra, Albernaz e Ferreira (2007), além dos dados do Instituto Ethos (2001). Tais colocações levaram à suposição de que as ações de responsabilidade socioambiental da empresa influenciam no comportamento de compra dos consumidores.

\section{Procedimentos metodológicos}

Nesta seção são retratados os desdobramentos da pesquisa realizados de acordo com as sugestões de estruturação encontradas na literatura sobre 0 assunto. A importância da estruturação metodológica, segundo Severino (1996), reside na própria natureza do trabalho científico; é aí, propriamente, que ocorre a efetivação do conhecimento científico.

\subsection{Tipos de pesquisas}

A classificação quanto aos tipos de pesquisa sugere três tipologias consideradas mais comuns na área de marketing: exploratória, descritiva e causal (BOYD; WESTFALL, 1987; AAKER, KUMAR; DAY, 2001; MALHOTRA, 2001; McDANIEL; GATES, 2003). A diferença básica entre pesquisa descritiva e causal reside no tipo de resposta que se busca. $\mathrm{Na}$ pesquisa causal, procura-se identificar as razões para o consumidor se comportar de uma determinada maneira. Na pesquisa descritiva, procura-se identificar o perfil do consumidor (o que, onde, quanto e quando compra). Diferentes tipos de pesquisa, segundo Mattar (1997), demandam diferentes adoções de procedimentos no que se refere à formulação das questões de pesquisa, métodos de coleta de dados e análise dos resultados, pois todos esses aspectos devem atender aos objetivos do estudo.

Tomando-se por base as considerações acima, a fase inicial do estudo foi permeada pela pesquisa exploratória de natureza bibliográfica, por meio da consulta de dados secundários, como livros, artigos científicos, monografias e dissertações de mestrado. Nesta fase, o objetivo foi identificar literaturas que subsidiassem a construção da base teórica.

0 objetivo da pesquisa exploratória, segundo Malhotra (2001), é explorar um problema ou 
situação para prover compreensão sobre o tema estudado. Por essa razão, é importante tal realização nos primeiros estágios da investigação (MATTAR, 1997; RICHARDSON, 1999). A justificativa para o levantamento bibliográfico, de acordo com Gil (2002), consiste no fato de permitir ao investigador a cobertura de uma gama de fenômenos muito mais ampla do que aquela que poderia pesquisar diretamente.

\subsection{Método}

Quanto aos métodos de pesquisa, Mattar (1997) os chama, respectivamente, de levantamento de campo e estudo de campo, ao passo que Boyd e Westfall (1987) os concedem sob a ótica de método estatístico e método de caso. Considerando que o foco do estudo foi verificar em uma única instituição, localizada na cidade de Orlândia-SP, se o comportamento dos consumidores pesquisados apresentava uma postura favorável em relação às questões socioambientais (OTTMAN, 1999; GILG; BARR; FORD, 2005; GREENDEMERS; PELLETIER; MENARD, 1997; HAYTKO; MATULICH, 2008), o método de pesquisa de caráter quantitativo descritivo apresentou-se como o caminho mais adequado neste estudo na segunda fase.

0 método quantitativo descritivo, na concepção de Richardson (1999), possibilita a quantificação de dados coletados. Tal opção permite que o pesquisador inicie, a partir de um conjunto de resultados, uma abordagem dedutiva ou indutiva, quando fizer uso de amostra, observando apenas uma parte dos casos (TRUJILLO, 2001). Assim, em face da natureza do objetivo proposto, a pesquisa apresenta um caráter conclusivo, também denominada por Mattar (1997) de pesquisa descritiva.

\subsection{Universo ou população do estudo}

0 primeiro procedimento para escolha da população consiste na delimitação da unidade que irá constituir o caso em estudo. Este pode ser composto de: pessoas, comunidades, culturas, empresas, conjunto de relação ou processos etc. (GlL, 2002). 0 universo ou população de pesquisa, segundo Mattar (1997), é representado pelo agregado de todos os casos pertinentes a um conjunto de especificações previamente estabelecidas.

Diante do exposto, o universo desta pesquisa foi constituído pelos 100 alunos do Curso de Administração da Faculdade de Orlândia (FAO), situada no município de Orlândia-SP. Desse total, 68 questionários foram considerados na análise por terem sido respondidos corretamente, 10 questionários foram devolvidos em branco, pois nem todos os alunos estavam presentes no dia da aplicação e 22 foram descartados por apresentarem falhas no seu preenchimento.

\subsection{Instrumento e técnicas de coleta de dados}

0 elemento mais importante do delineamento de uma pesquisa é o procedimento adotado para a coleta de dados, denominada de fase do método de pesquisa, que tem por objetivo, obter informações da realidade (GlL, 2002). Assim, o instrumento utilizado para coletar os dados primários deste estudo foi o questionário estruturado, uma vez que o objetivo dos pesquisadores foi seguir um único roteiro de perguntas para todos os respondentes, conforme sugerido por Mattar (1997). Sua aplicação foi realizada em sala de aula, pelos próprios pesquisadores, ao longo do mês de outubro de 2007, com tempo de aproximadamente 20 minutos para preenchimento.

Em função do caráter quantitativo, os questionários foram desenvolvidos com base em um conjunto de quarenta questões fechadas e relacionadas com os objetivos e com o problema de pesquisa. As variáveis que subsidiaram a elaboração do questionário foram baseadas no Modelo SERVQUAL (Qualidade de Serviço), desenvolvido por Zeithaml, Parasuraman e Berry (1990), e amplamente utilizado em pesquisas que o adaptaram de acordo com o objeto de estudo no contexto de avaliação da qualidade em serviços (PARASURAMAN, ZEITHAML; BERRY, 1985; ROBINSON, 1999; ROBLEDO, 2001; ELEUTÉRIO; SOUZA, 2002).

No questionário, os respondentes indicavam um grau de "concordância" ou "discordância" em relação às afirmações contempladas, com numeração baseada na Escala de Likert, variando de 1 (Discordo Totalmente) a 5 (Concordo Totalmente). Tais questionários foram divididos em dois blocos: no primeiro constavam dez questões de caracterização dos respondentes. No segundo, as 30 questões (17 sobre percepções dos consumidores sobre responsabilidade socioambiental e 13 sobre responsabilidade socioambiental e decisão de compra no consumo) foram acopladas a uma escala de percepção, que varia entre "sim”, "não”, "nunca", "sempre".

No tocante às técnicas de se coletar os dados ao longo da pesquisa de campo, existem diferentes maneiras de fazê-lo, tais como entrevista pessoal, entrevista por telefone e autoadministradas (COOPER; SCHINDLER, 2003). Nesta pesquisa, optou-se pelo método pessoal, de modo que os questionários fossem aplicados pessoalmente pelos pesquisadores,

\subsection{Pré-teste}

Segundo Aaker, Kumar e Day (2001), as primeiras versões dos questionários costumam ser longas demais, sem algumas variáveis importantes, e podem estar 
sujeitas a todo tipo de problemas, com questões ambíguas, tendenciosas ou mal elaboradas. Assim, o objetivo do pré-teste é propiciar a correção dessas deficiências e tendenciosidades. No intuito de se evitar os problemas aqui apontados, antes de partir para a etapa prática da pesquisa, foi realizado um pré-teste com cinco indivíduos não pertencentes ao público-alvo, que teve como objetivo identificar possiveis falhas inerentes ao questionário, tais como: complexidade das questões, imprecisão na redação, falta de clareza e objetividade, inconsistência e inadequação ao objetivo proposto pelos pesquisadores.

Os resultados do pré-teste mostraram que o questionário, além de apresentar falhas em algumas questões, demandava grande tempo para sua realização, devido a sua extensão e complexidade. De posse desse importante resultado, elaborou-se uma nova versão do questionário para, então, aplicá-lo ao público-alvo.

\subsection{Tratamento dos dados}

Nesta etapa, o objetivo foi identificar qual variável possuía maior ou menor escala de ocorrência percentual. Para tanto, o processo de análise dos dados foi conduzido por meio da criação de indicadores de síntese da informação, através da probabilidade estatística percentual $(P)(1)$, conforme expressões a seguir (SILVER, 2000).

$$
P=\frac{A \times 100}{T}
$$

Onde: $\mathrm{P}$ = Probabilidade estatística percentual; $\mathrm{A}=$ Quantidade de respostas para determinada variável em determinada escala de ocorrência; $\mathrm{T}=$ Total de questionários aplicados para cada período analisado.

A probabilidade estatística percentual baseia-se em observações obtidas de experimentos estatísticos probabilísticos, ou seja, é a frequência relativa percentual do evento considerado. As escalas de ocorrência utilizadas neste trabalho são eventos das diferentes variáveis analisadas (LARSON; FARBER, 2004). Dessa forma, é possível verificar qual variável possui a maior e/ou menor escala de ocorrência porcentual. A expressão utilizada foi a (2).

$$
\bar{x}=\frac{\sum_{i=1}^{n} \frac{M}{T}}{n} \times 100
$$

Onde: $\mathrm{x}$ - média aritmética normalizada; $\mathrm{M}$ - total de respostas para cada escala de atitude; $\mathrm{T}$ - total de questionários aplicados para cada curso; $\mathbf{n}$ - total de variáveis analisadas.
Como o objetivo foi aprofundar a avaliação da influência da responsabilidade socioambiental sobre as decisões de compra dos consumidores, optou-se por aplicar aos dados a análise de clusters, também denominada de "conglomerados", porque, segundo Everitt (1993), trata-se de uma técnica estatística que permite agrupar e classificar os indivíduos com características semelhantes, em função de um conjunto de variáveis selecionadas.

\section{Apresentação e discussão dos resultados}

A seguir são apresentados os resultados da presente pesquisa, permeados com as análises respaldadas no referencial teórico.

\subsection{Caracterização do perfil dos respondentes}

Os respondentes apresentaram as características socioculturais observadas nas Tabelas 1 e 2 .

A Tabela 1 revela que a faixa etária predominante da população pesquisada fica entre 20 e 30 anos, revelando, assim, um grupo relativamente jovem $(64,5 \%)$. Observa-se que $23,5 \%$ dos respondentes apresentam idade entre 30 e 40 anos; $9 \%$ estão entre 40 e 50 anos, e, apenas 3\% estão na faixa abaixo dos 20 anos. Os resultados referentes ao gênero e ao estado civil constam nas Tabelas 2A,B.

Conforme pode ser observado na Tabela 2, verifica-se que a maior parte da população pesquisada é representada pelo sexo masculino. Os resultados mostram ainda que a maioria da população pesquisada é solteira.

Tabela 1. Faixa etária da população pesquisada.

\begin{tabular}{ccc}
\hline Faixa etária & Frequência & Porcentual (\%) \\
\hline Menos de 20 & 2 & 3 \\
Entre 20 e 30 & 44 & 64,5 \\
Entre 30 e 40 & 16 & 23,5 \\
Entre 40 e 50 & 6 & 9 \\
Entre 50 e 60 & 0 & 0 \\
Mais de 60 & 0 & 0 \\
Total & 68 & 100
\end{tabular}

Tabela 2. Gênero e Estado Civil dos respondentes.

\begin{tabular}{ccc}
\hline A - Gênero & Porcentagem (\%) & Frequência \\
\hline Masculino & 71 & 48 \\
Feminino & 29 & 20 \\
\hline B - Estado civil & Porcentagem (\%) & Frequência \\
\hline Solteiro & 55 & 37 \\
Casado & 42 & 28 \\
Outros & 3 & 2 \\
\hline
\end{tabular}

Fonte: dados da pesquisa de campo. 


\subsection{Percepção dos consumidores sobre a Responsabilidade Social}

Sobre a questão se "já compraram produtos de empresas que praticam ações de responsabilidade socioambietal”, os resultados indicam que 44 dos 68 respondentes (64\%) disseram que "sim" e 15, que "não" (22\%). Ou seja, a maioria tem compensado os esforços das empresas. As respostas referentes à questão que analisou as percepções dos respondentes sobre os "motivos, que levam as empresas a praticarem ações de Responsabilidade Social”, estão ilustradas na Figura 1.

É possível observar pela disposição dos resultados da Figura 1 que a maioria dos respondentes acredita que as empresas praticam ações de responsabilidade socioambiental porque querem "melhorar a imagem da organização", conforme comentário de Ashley et al. (2005). 0 segundo motivo mais indicado sugere que elas o fazem para "ajudar as comunidades carentes". Os demais motivos receberam menos indicações. Os resultados referentes à questão que procurou investigar se os respondentes "já adquiriram produtos ou serviços motivados pelas ações de Responsabilidade Social” estão demonstrados na Figura 2.

Os resultados da Figura 2 sugerem que uma pequena parcela dos respondentes vincula suas compras às ações de responsabilidade socioambiental, mas, no geral, eles não levam esses aspectos em consideração. "Os principais aspectos que levam em consideração no momento da compra”, podem ser visualizados na Figura 3.

As declarações da Figura 3 demonstram que a "maior pontuação" foi atribuída ao item "prazo/forma de pagamento" ao passo que a "menor pontuação" foi atribuída ao item "Responsabilidade Social". Parece ficar claro que a "marca", a "qualidade" e o "preço", são as variáveis mais importantes. Estas declarações vão ao encontro das respostas obtidas na pergunta que procurou indagar se "estavam dispostos a pagar um preço mais alto por produtos ecológicos" (Figura 4).

Percebe-se, pela Figura 4, que apenas uma pequena parcela dos 68 respondentes "estaria disposta a pagar mais por produtos ecológicos”, ao passo que uma boa parte assumiu que "não estaria disposta a fazêlo". Os demais respondentes limitaram-se a declarar que "as vezes paga mais por isso"; que "raramente o fazem" ou que "nunca o fez".

\subsection{Discussão dos resultados}

Depreende-se dos resultados que os objetivos propostos foram alcançados: os dados coletados por meio da pesquisa de campo revelam que, de forma geral, os consumidores têm noção do que é Responsabilidade Social, pois demonstraram que estão informados a esse respeito. Constatou-se, por exemplo, que, dentre os 68 respondentes, 64\% declararam "já terem comprado" produtos de empresas que sabem que estão envolvidas em ações socioambientais. Esse fato vai ao encontro das premissas respaldadas por Trevisan (2002), as quais apontam que 24\% de 1.002 brasileiros que declaram ter prestigiado uma empresa socialmente responsável, comprando seus produtos ou falando bem dela para outras pessoas, e 19\% que disseram ter punido uma empresa em situação oposta, fazendo o contrário.

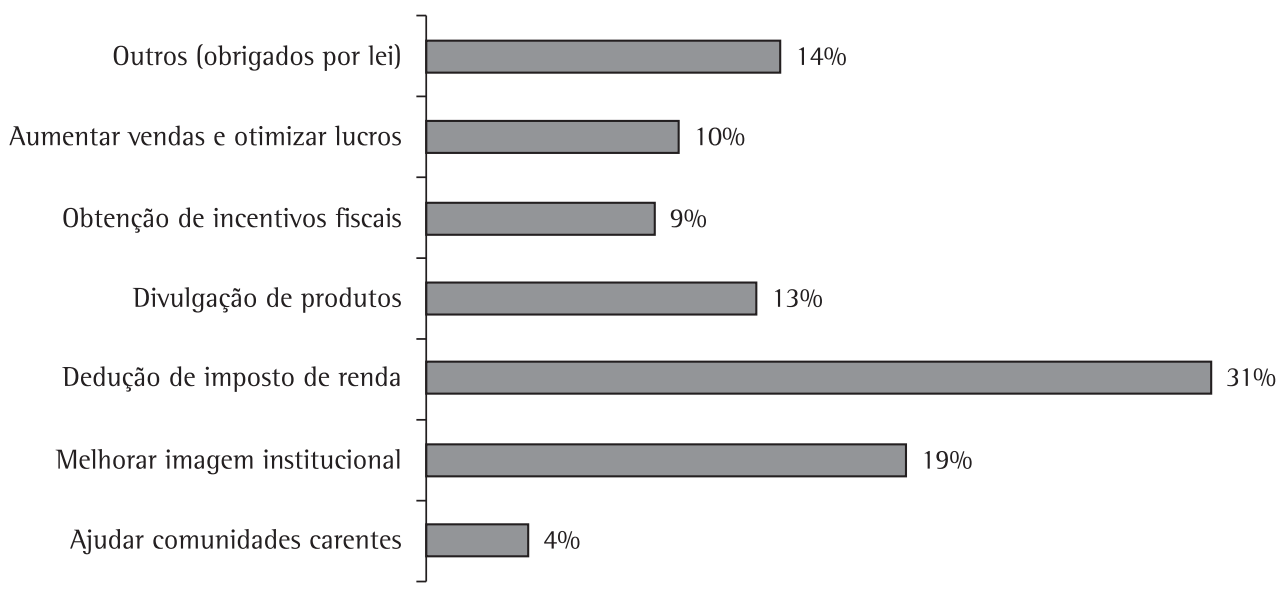

Figura 1. Motivos que levam as empresas a praticarem Responsabilidade Social, segundo os consumidores. Fonte: dados da pesquisa de campo. 


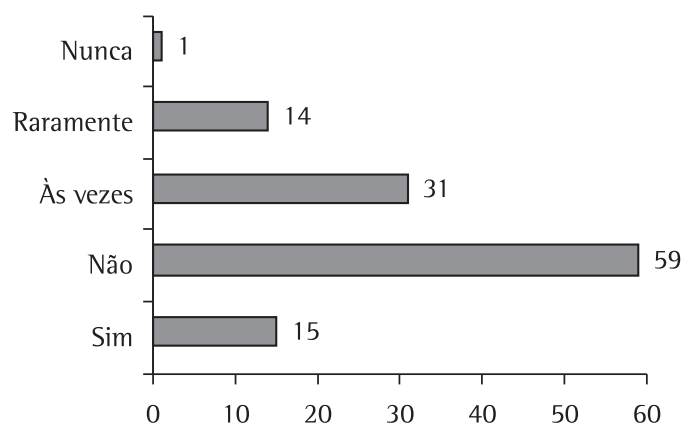

Figura 2. Compras vinculadas à Responsabilidade Social. Fonte: dados da pesquisa de campo.

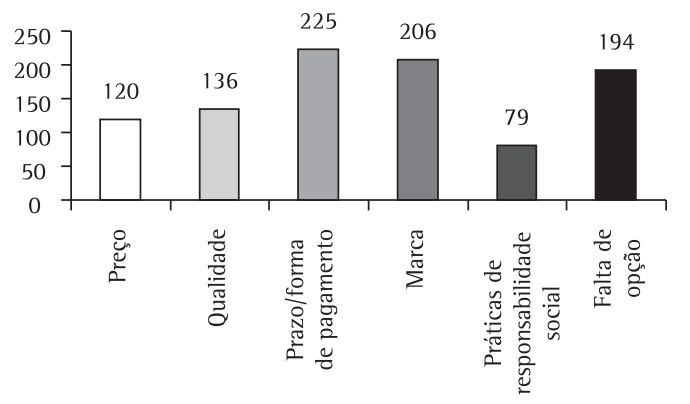

$$
\begin{array}{ll}
\square \text { Preço } & \square \text { Qualidade } \\
\square \text { Prazo/forma de pagamento } & \square \text { Marca } \\
\square \text { Práticas de responsabilidade social } & \square \text { Falta de opção }
\end{array}
$$

Figura 3. Aspectos levados em consideração no momento da compra. Fonte: dados da pesquisa de campo.

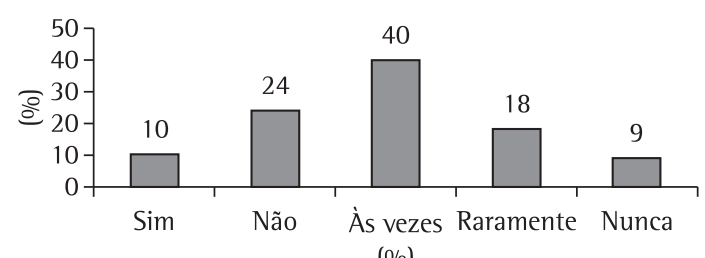

$(\%)$

Figura 4. Disposição do consumidor a pagar mais por um produto ecológico. Fonte: dados da pesquisa de campo.

Por outro lado, constatou-se que a conclusão da pesquisa de Brown e Dacin (1997), que defendia a ideia de que a RSC exerce influência positiva nas crenças e atitudes dos consumidores, não constitui uma verdade absoluta, tendo em vista que dentre os 68 respondentes, apenas 13\% deles (15), declararam que ao "fazer compras" levam em consideração os aspectos relacionados à Responsabilidade Social e 48\% declararam que "não levam em consideração este aspecto”. Tais resultados acabaram, por assim dizer, refutando a proposição formulada neste estudo, que consistia na suposição de que "as ações de Responsabilidade Social exerciam influência sobre as decisões de compra dos consumidores pesquisados na cidade de Orlândia”.

Outros aspectos foram evidenciados nos resultados obtidos: 31\% dos respondentes enxergam as ações de Responsabilidade Social como uma maneira que as empresas utilizam para "melhorar a imagem no mercado". Adicionalmente a isso, tem-se que $41 \%$ dos respondentes "não lembram" de terem comprado produtos ou serviços motivados pelas ações de Responsabilidade Social; e 18\% "não" adquiriram produtos motivados por tais ações. Parece ter ficado claro também, que 31\% dos respondentes apresentam uma visão negativa quanto às ações sociais praticadas pelas empresas. Isso fica demonstrado quando declararam que "consideram os "produtos ecológicos' como um 'jogo de marketing”, o que permite inferir que existe uma certa descrença em relação a essas ações.

\section{Considerações finais}

Tomando por base as discussões construídas a partir dos resultados analisados, conclui-se que, muito embora os consumidores pesquisados por meio da pesquisa de campo tenham revelado que, de forma geral, valorizam as ações de Responsabilidade Social e tenham declarado que já compraram produtos de empresas que estão envolvidas em ações socioambientais, tais ações "não influenciam nas suas decisões de compra”. Conclui-se, ainda, que apenas uma pequena parcela dos respondentes pode ser considerada como "consumidores conscientes", ao passo que, por alguma razão, a maioria dos consumidores ainda não está contribuindo para a perpetuação do exercício da responsabilidade socioambiental.

Assim, sem a pretensão de resolver os problemas identificados, sugerem-se alguns fatores que podem culminar em possiveis atitudes que coloquem as ações de Responsabilidade Social das empresas em uma melhor sintonia com os consumidores: que as empresas divulguem mais as suas ações de responsabilidade socioambiental, evidenciando os impactos positivos gerados para a biodiversidade e para a sociedade; e que façam campanhas que sensibilizem não apenas os aspectos "emocionais" dos consumidores, mas também, os aspectos relacionados à conscientização de que o exercício da responsabilidade social e ambiental é um processo que só irá perpetuar se "todos" abraçarem a mesma causa - empresas e consumidores. 


\section{Limitações do estudo e sugestões para pesquisas futuras}

Neste tópico são elencadas as limitações da pesquisa com o intuito de propiciar ao leitor uma interpretação mais precisa dos resultados aqui apresentados. Nesse sentido, Selltiz, Wrightsman e Cook (1974) fazem as seguintes recomendações: a) que os pesquisadores apresentem as características específicas da metodologia, que podem ter influenciado nos resultados, ou possíveis falhas na pesquisa, que podem ter limitado a extensão das generalizações; b) que os pesquisadores discutam as diferenças quanto às características da amostra em relação à população, para a qual se gostaria de generalizar os dados obtidos.

Diante de tais recomendações, procurou-se estruturar este tópico, de modo que esses dois aspectos sejam discutidos, pois, como toda pesquisa científica, esta apresentou algumas limitações, que poderão ser superadas em estudos futuros: a) em relação aos indicadores: foram utilizados praticamente os mesmos indicadores encontrados na literatura, com pequenas modificações em determinadas questões, apesar do cuidado de se ter averiguado sua adequação à realidade do universo selecionado; b) em relação à dimensão da amostra: a amostra utilizada neste estudo restringe-se apenas a um público específico da cidade de Orlândia. Por conta disso, tal amostra não pode ser generalizada ou estendida a toda a população da área geográfica selecionada e para todo o Estado de São Paulo. Além do mais, esse primeiro estudo com os alunos de Orlândia constitui uma pesquisa piloto para adequar o questionário para uma pesquisa maior, daí o motivo pelo qual os resultados aqui discutidos não podem ser generalizados para toda a população.

Dadas às limitações aqui apontadas, acredita-se que uma análise comparativa poderia conduzir a uma visão mais ampla sobre o tema pesquisado neste estudo: realizar esse mesmo estudo, procurando identificar como os próprios empresários percebem o comportamento dos consumidores em relação às suas ações socioambientais; procurar verificar junto às empresas, por que continuam investindo em ações socioambientais, se na prática os consumidores parecem não valorizá-las tanto quanto dizem na teoria.

Além das sugestões de pesquisa lançadas como propostas de estudos futuros, ressalta-se a importância de ampliar os resultados obtidos para a implementação de um estudo que procurasse comparar as percepções dos empresários com as percepções de alguns agentes envolvidos ao longo da cadeia de distribuição, como, por exemplo, fornecedores ou distribuidores.
Como o papel de toda e qualquer pesquisa científica é dar a sua contribuição à sociedade e à academia, espera-se que o estudo possa contribuir para a comunidade empresarial, em função dos resultados aqui discutidos e das sugestões, enquanto possíveis alternativas de equacionamento das deficiências encontradas. Espera-se, também, que a quantidade e a qualidade dos textos utilizados possam servir como fonte de referência bibliográfica em outras pesquisas, e que as discussões apresentadas possam inspirar a implementação de outros estudos no setor ou, até mesmo, em outros setores da economia.

\section{Referências}

AAKER, D. A. Measuring brand equity across products and markets. California Management Review, v. 38, n. 3, p. 102-120, 1996.

AAKER, D. A.; KUMAR, V.; DAY, G. S. Pesquisa de marketing. São Paulo: Atlas, 2001.

AJZEN, 1. The theory of planned behavior. Organizational Behavior and Human Decision Process, v. 50, n. 2, p. 179-211, 1991. http://dx.doi.org/10.1016/07495978(91)90020-T

AMINE, L. S. An integrated micro- and macrolevel discussion of global green issues: "It isn't easy being green'. Journal of International Management, v. 9, n. 4, p. 373-393, 2003. http://dx.doi.org/10.1016/j.intman.2003.08.002

ANTONIDES, G.; RAAIJ, F. V. Consumer behavior: a European perspective. Chichester: John Wiley \& Sons, 1998.

ASHLEY, P. A. et al. Ética e responsabilidade social nos negócios. São Paulo: Saraiva, 2005.

ATUAHENE-GIMA, K. Market orientation and innovation. Journal of Business Research, v. 35, n. 2, p. 93-103, 1996. http://dx.doi.org/10.1016/0148-2963(95)00051-8

BÄCKSTROÖM, K.; JOHANSSON, U. Creating and consuming experiences in retail store environments: Comparing retailer and consumer perspectives. Journal of Retailing and Consumer Services, v. 13, n. 6, p. 417-430, 2006. http://dx.doi.org/10.1016/j.jretconser.2006.02.005

BOYD, H. W.; WESTFALL, R. Pesquisa mercadológica: textos e casos. Rio de Janeiro: Editora da Fundação Getulio Vargas, 1987.

BROWN, T. J.; DACIN, P. A. The Company and the Product: Corporate Associations and Consumer Product Responses. Journal of Marketing, v. 61, n. 1, p. 68-84, 1997. http:// dx.doi.org/10.2307/1252190

CARRIGAN, M. Positive and Negative Aspects of the Societal Marketing Concept: Stakeholder Conflicts for the Tobacco Industry. Journal of Marketing Management, v. 11, n. 5, p. 469-485, 1995. http://dx.doi.org/10.1080/ 0267257X.1995.9964359

CHURCHIL, G. A.; PETER, P. J. Marketing: criando valor para o cliente. Tradução de Cecília Camargo Bartalotti; Cid Knipel Moreira. São Paulo: Saraiva, 2000.

COOPER, D. R.; SCHINDLER, P. S. Métodos de Pesquisa em Administração. 7. ed. Porto Alegre: Bookman, 2003.

COSTA, A. 1. A; JONGEN, W. M. F. New insights into consumerled food product development. Trends in Food Science \& Technology, v. 17, p. 457-465, 2006. PMid:21299575. http://dx.doi.org/10.1016/j.tifs.2006.02.003 
D’AMBROS10, D. Investir em ética pode ser um bom negócio. Gazeta Mercantil, São Paulo, Caderno C-8, 27 jul. 1998.

DEMIRDJIAN; Z. S.; SENGUDER, T. Perspectives in Consumer Behavior: Paradigm Shifts in Prospect. Journal of American Academy of Business, v. 4, n. 1-2, p. 348-363, 2004.

DICK, A.; CHAKRAVARTI, D.; BIEHAL, G. Memory-Based Inferences During Consumer Choice. Journal of Consumer Research, v. 17, n. 1, p. 82-93, 1990. http:// dx.doi.org/10.1086/208539

DOWLING, G. R. Developing your company image into a corporate asset. Long Range Planning, v. 26, n. 2, p. 101-109, 1993. http://dx.doi.org/10.1016/00246301(93)90141-2

DRUCKER, P. Sociedade Pós-Capitalista. São Paulo: Pioneira, 2001.

ELEUTÉRIO, S. A. V.; SOUZA, M. C. A. F. Qualidade na Prestação de Serviços: uma avaliação com clientes internos. Caderno de Pesquisas em Administração, v. 09, n. 3, p. 53-64, 2002.

ENGEL, J. F.; BLACKWELL, R. D.; MINIARD, P. W. Consumer behavior. 8. ed. Forth Worth: The Dryden Press, 1995.

EVERITT, B. S. Cluster analysis. London: Hodder \& Stoughton, 1993.

FEDATO, M. C. L. Responsabilidade Social Corporativa: benefício social ou vantagem competitiva? Um estudo das estratégias de atuação social empresarial e sua avaliação de resultados. 2005. Dissertação (Mestrado em Administração)-Faculdade de Economia, Administração e Contabilidade da Universidade de São Paulo, São Paulo, Brasil, 2005.

FOMBRUN, C.; GARDBERG, N. A.; BARNETT, M. L. Opportunity Platforms and Safety Nets: Coporate Citizenship and Reputational Risk. Business and Society Review, v. 105, n. 1, p. 85-106, 2000. http://dx.doi. org/10.1111/0045-3609.00066

FORTES, M. Desenvolvimento e meio ambiente: a visão empresarial. In: VEllOSO, J. P. R. et al. (Orgs.). $A$ ecologia e o novo padrão de desenvolvimento no Brasil. São Paulo: Nobel, 1992.

FREITAS, M. E. Contexto social e imaginário organizacional moderno. In: ENCONTRO ANUAL DA ASSOCIAÇÃO NACIONAL DE PÓS-GRADUAÇÃO E PESQUISA EM ADMINISTRAÇ̃̃O - ANPAD, 21., 1997, Angra dos Reis. Anais... Rio de Janeiro: ANPAD, 1997.

FRIEDMAN, M. Capitalismo e liberdade. 3. ed. São Paulo: Nova Cultural, 1988.

GlL, A. C. Gestão de pessoas: enfoque nos papéis profissionais. São Paulo: Atlas, 2001.

GlL, A. C. Como elaborar projetos de pesquisa. São Paulo: Atlas, 2002.

GILG, A.; BARR, S.; FORD, N. Green consumption or sustainable lifestyles? ldentifying the sustainable consumer. Futures, v. 37, p. 481-504, 2005. http:// dx.doi.org/10.1016/j.futures.2004.10.016

GOMES, D. V. Educação para o consumo ético e sustentável. Revista Eletrônica do Mestrado em Educação Ambiental, v. 16, p. 18-31, 2006.

GREEN-DEMERS, I.; PELLETIER, L. G.; MENARD, S. The Impact of Behavioural Difficulty on the Saliency of the Association Between Self-Determined Motivation and Environmental Behaviours. Canadian Journal of
Behavioural Science, v. 29, n. 3, p.157-166, 1997. http:// dx.doi.org/10.1037/0008-400X.29.3.157

HAYTKO, D. L.; MATULICH, E. Green Advertising and Environmentally Responsible Consumer Behaviors: Linkages Examined. Journal of Management and Marketing Research, v. 1, p. 2-11, 2008.

INSTITUTO ETHOS. Indicadores Ethos de Responsabilidade Social. Disponivel em: <http://www.ethos.org.br/docs/ conceitos_praticas/indicadores/resultados_2001>. Acesso em: 12 ago. 2007.

JACOBY, J.; KYNER, D. Brand Loyalty Vs. Repeat Purchasing Behavior. Journal of Marketing Research, v. 10, n. 1, p. 1-9, 1973. http://dx.doi.org/10.2307/3149402

KLEEF, E.; TRIJP, H. C. M.; LUNING, P. Consumer Research in The Early Stages of New Product Development: a critical review of methods and techniques. Food Quality and Preference, v. 16, n. 3, p. 181-201, 2005. http://dx.doi. org/10.1016/j.foodqual.2004.05.012

KOTLER, P.; ARMSTRONG, G. Princípios de marketing. 5. ed. Rio de Janeiro: Prentice-Hall do Brasil Ltda, 1993.

KOTLER, P.; KELLER, K. L. Administração de marketing. 12. ed. São Paulo: Pearson Prentice Hall, 2006.

LARSON, R.; FARBER, B. Estatística aplicada. 2. ed. São Paulo: Prentice Hall, 2004.

LEVEK, A. R. H. C. et al. A Responsabilidade Social e sua interface com o marketing social. Revista da $F A E$, v. 5 , n. 2, p. 15-25, 2002.

LEVY, S. J. The evolution of qualitative research in consumer behavior. Journal of Business Research, v. 58 , p. 341-347, 2005. http://dx.doi.org/10.1016/S01482963(03)00107-3

LIMA, F. R. Responsabilidade Social de uma Empresa: o caso da Souza Cruz S.A. conforme a ótica dos seus gerentes. 2002. 104 f. Dissertação (Mestrado em Administração)-Universidade Federal do Rio Grande do Sul, Porto Alegre, 2002.

MACKENZIE, D. The Green Consumer. Food Policy, v. 15, n. 6, p. 461-466, 1990. http://dx.doi.org/10.1016/03069192(90)90036-Y

MALHOTRA, N. K. Pesquisa de Marketing: uma Orientação Aplicada. Porto Alegre: BOOKMAN, 2001.

MATTAR, F. N. Pesquisa de Marketing. 3. ed. São Paulo: Atlas, 1997.

McDANIEL, C.; GATES, R. Pesquisa de marketing. São Paulo: Pioneira Thomson Learning, 2003.

MELO NETO, F. P. M.; FROES, C. Responsabilidade Social \& Cidadania Empresarial: a administração do terceiro setor. Rio de Janeiro: QualityMark, 1999.

MINTU-WIMSATT, A. T.; BRADFORD, D. M. In search of market segments for green products. In: POLONSKY, M. J.; MINTU-WIMSATT, A. T. (Eds.). Environmental marketing: strategies, practice, theory, and research. Nova York: Haworth, 1995.

MOHR, L. A.; WEBB, D. J. The Effects of Corporate Social Responsibility and Price on Consumer Responses. The Journal of Consumer Affairs, v. 39, n. 1, p. 121-147, 2005. http://dx.doi.org/10.1111/j.1745-6606.2005.00006.x

MOHR, L. A.; WEBB, D. J.; HARRIS, K. E. Do Consumers Expect Companies to be Socially Responsible? The Impact of Corporate Social Responsibility on Buying Behavior. Journal of Consumer Affairs, v. 35, n. 1, p. 45-72, 2001. http://dx.doi.org/10.1111/j.1745-6606.2001.tb00102.x 
MORAIS, M. R. B. et al. Marketing Social: Os Reflexos na Relaç̧ão entre Empresas e Consumidores. In: ENCONTRO ANUAL DA ASSOCIAÇÃO NACIONAL DE PÓS-GRADUAÇÃO E PESQUISA EM ADMINISTRAÇÃO - ENANPAD, 30., 2006, Salvador. Anais... Salvador: ANPAD, 2006.

MOTTA, S. L. S.; ROSSI, G. B. A influência do fator ecológico na decisão de compra de bens de conveniência. Revista de Administração Mackenzie, ano 2, n. 2, p. 109-130, 2001.

NICOSIA, F. Consumer decision processes: marketing and advertising implications. Englewood Cliffs, New Jersey: Prentice-Hall, 1966.

OTTMAN, J. A. Green marketing: Will the consumer pay a premium for green? In Business, v. 21, n. 4, p. 36, 1999.

PARASURAMAN, A.; ZEITHAML, V. A.; BERRY, L. L. A conceptual model of service quality and its implication for future research. Journal of Marketing. v. 49, n. 4, p. 41-50, 1985. http://dx.doi.org/10.2307/1251430

PROGRAMA DAS NAÇÕES UNIDAS PARA 0 DESENVOLVIMENTO - PNUD. Consumo sustentável. Tradução de Admond Ben Meir. São Paulo: Secretaria do Meio Ambiente, IDEC, Consumers International, 1998.

RICHARDSON, R. J. Pesquisa Social: métodos e técnicas. 3. ed. São Paulo Atlas: 1999.

ROBINSON, S. Measuring service quality: current thinking and future requirements. Marketing Intelligence \& Planning, v. 17, n. 1, p. 21-32, 1999. http://dx.doi. org/10.1108/02634509910253777

ROBLEDO, M. A. Measuring and managing service quality: integrating customer expectations. Managing Service Quality, v. 11, n. 1, p. 22-31, 2001. http://dx.doi. org/10.1108/09604520110379472

SELLTIZ, C.; WRIGHTSMAN, L.; COOK, S. W. Métodos de pesquisa nas relações sociais. São Paulo: EPU, 1974.

SERRA, F. A.; ALBERNAZ, A.; FERREIRA, M. P. A Responsabilidade Social como Fator na Estratégia Internacional: 0 Estudo do Caso Natura. REAd, v. 13, n. 4, ed. especial 58, p. 1-23, 2007.

SEVERINO, A. J. Metodologia do trabalho científico. São Paulo: Cortez, 1996.
SHETH, J. N.; MITTAL, B.; NEWMAN, B. 1. Comportamento do cliente: indo além do comportamento do consumidor. Tradução de Antonio Carlos de Almeida. São Paulo: Atlas, 2001.

SILVER, M. Estatística para Administração. São Paulo: Atlas, 2000

SOLOMON, M. R. Consumer Behavior. Needham Heights: Allyn \& Bacon, 1996.

SROUR, R. H. Poder, cultura e ética nas organizações. 8. ed. Rio de Janeiro: Campus, 1998.

THOGERSEN, J.; OLANDER, F. Human values and the emergence of a sustainable consumption pattern: a panel study. Journal of Economic Psychology, v. 23, n. 5, p. 605-630, 2002. http://dx.doi.org/10.1016/S01674870(02)00120-4

THUROW, L. O futuro do capitalismo: como as forças econômicas moldam o mundo do amanhã. Rio de Janeiro: Rocco, 1997.

TITUS, P. A.; BRADFORD, J. L. Reflections on Consumer Sophistication and lts Impact on Ethical Business Practice. Journal of Consumer Affairs, v. 30, n. 1, p. 170-195, 1996. http://dx.doi.org/10.1111/j.1745-6606.1996.tb00730.x

TOMEl, P. A.; LERNER, A. Os Modismos Gerenciais e a Dinâmica Organizacional. In: ENCONTRO ANUAL DA ASSOCIAÇÃO NACIONAL DE PÓS-GRADUAÇÃO E PESQUISA EM ADMINISTRAÇÃO - ANPAD, 21., 1997, Angra dos Reis. Anais... Rio de Janeiro: ANPAD, 1997.

TREVISAN, F. A. Balanço Social como Instrumento e Marketing. Revista RAE-eletrônica, v. 1, n. 2, jul./ dez. 2002.

TRUJILl0, V. Pesquisa de Mercado qualitativa \& quantitativa. São Paulo: Scortecci, 2001.

WAGNER, S. A. Understanding Green Consumer Behavior. a qualitative cognitive approach. London and New York: Routledge Taylor \& Francis Group, 2003.

ZEITHAML, V. A.; PARASURAMAN, A.; BERRY, L. L. Delivering quality service - balancing customer perceptions and expectations. New York: The Free Press, 1990.

\title{
Consumer socio-environmental behavior: a study with college students in the countryside of the State of Sao Paulo
}

\begin{abstract}
Corporate Social Responsibility is increasingly being consolidated within a very competitive market scenario comprising more selective and demanding consumers. Thus, the purpose of this research was to verify whether socio-environmental actions influence consumer purchase decision. To this end, 100 questionnaires were applied to undergraduate students from a business administration course at a university in the State of Sao Paulo; 68 questionnaires were validated and analyzed by descriptive statistics. Results showed that: i) socio-environmental actions do notaffect the purchase process of these consumers; ii) companies should inform consumers which social and environmental actions they are involved in and which positive impacts their actions have generated to biodiversity and society.
\end{abstract}

Keywords

Socio-environmental responsibility. Purchase decision. Consumer loyalty. Consumer behavior. 